\title{
TUBERCULOSIS IN NSW CORRECTIONAL CENTRES: DISEASE CONTROL MEASURES FOLLOWING INFECTIOUS CASES
} Stephen Conaty ${ }^{7}$,Amanda Christiansen', Tony Butler',
Jeremy McAnulty ${ }^{3}$, Hazel Goldberg ${ }^{4}$

\section{Public Health Officer, NSW Health Department}

2. Clinical Nurse Consultant in Public Health, Corrections Health Service

3. Medical Epidemiologist, AIDS/Infectious Diseases

Branch, NSW Health Department

4. Visiting Respiratory Physician, Prince of Wales Hospital

his article is a preliminary report on tuberculosis control measures carried out in two of the largest correctional centres in NSW, following four laboratory-confirmed cases diagnosed among inmates between January and April 1996. Two of the cases were assessed as having been infectious.

The Corrections Health Service, with the State Tuberculosis Coordinator (from the NSW Health Department's AIDS/Infectious Diseases Branch) and the South Eastern Public Health Unit, initiated contact tracing of almost 1,000 inmates and several hundred correctional centre personnel who had been in contact with the two infectious cases.

Contact tracing did not identify any new TB cases, but a high rate of TB infection among inmates was found. An epidemiological investigation into the relationship between the cases and risk factors for transmission is to follow.

\section{CASES}

The four cases, all males, ranged in age from 26 to 43 years. All were overseas born; three had lived in Australia for more than 10 years, while the fourth had arrived two years previously.
- Case 1 was diagnosed with TB in January 1996, six months into his sentence. He had a history of periodic shortness of breath, and a chest $\mathrm{x}$-ray in October 1995 showed left upper lobe changes. Direct sputum smear was negative for acid-fast bacilli, and a smear of bronchial washings was also negative, but culture of the bronchial washings was positive. Case 2 was also diagnosed in January 1996, one month into his sentence. He had a two-month history of weight loss, fever, night sweats and cough. Chest $\mathrm{x}$-ray suggested predominantly pleural disease. One out of six sputum smears was positive for acid-fast bacilli which were present in low numbers.
- Case 3 was diagnosed in February 1996, six months into his sentence, after a prolonged history of cough. Chest $\mathrm{x}$-ray showed bilateral upper lobe active changes. Direct sputum smear was positive for acid- fast bacilli.
घ Case 4 was diagnosed in April 1996, 18 months into his sentence, after a six-month history of sore throat, cervical lymphadenopathy, weight loss and cough. Chest x-ray showed an active lesion in the right upper lobe, and a miliary pattern throughout the lung fields. Direct sputum smear was positive for acid-fast bacilli.

Cases 1 and 2 were considerd to be of low infectivity, but Cases 3 and 4 were considered to be infectious. Case 3 was presumed to have been infectious for three months, and Case 4 for six months, before diagnosis.

\section{METHODS}

Mantoux screening of contacts of Cases 3 and 4 was begun in March and May 1996 respectively. Contacts were defined broadly, and included all cell-mate (sharing a prison cell with an infectious case), wing-mate (in a cell sharing a prison wing with an infectious case), education and workplace contacts during the infectious period. Prison authorities compiled lists of contacts.

Corrections Health clinic staff and local chest clinic staff administered and read Mantoux tests at 72 hours. The criteria for Mantoux test positivity were defined as follows:

\begin{tabular}{l|l} 
\\
$\square$
\end{tabular} \mid $\begin{aligned} & \mathrm{m} \mathrm{mm} \text { for cell-mate contact or contacts who were } \\
& \geq 10 \mathrm{~mm} \text { in the absence of a history or evidence of th } \\
& \text { contact having received BCG vaccination in the } \\
& \text { previous } 10 \text { years; and } \\
& \geq 15 \mathrm{~mm} \text { if there was a history and evidence of the } \\
& \text { contact having received BCG in the previous } \\
& 10 \text { years. }\end{aligned}$

Known HIV-positive contacts were also evaluated for falsenegative Mantoux because of skin-test anergy by the cellmediated immunity multi-skin test.

Countries of birth, previous BCG, presence of BCG scar, and history of TB, were recorded at the time of Mantoux testing.

A second round of Mantoux screening was offered to Mantoux-negative inmate contacts to detect Mantoux conversions in September 1996.

Mantoux-positive inmates from first and second rounds of testing were offered chest $x$-rays, as were cell-mate contact and known HIV-positive inmates. In both correctional centres mobile chest $\mathrm{x}$-rays were made available for inmates. Staff with positive Mantoux reactions were referred to chest clinics in the community. Inmates' chest $\mathrm{x}$-rays were forwarded to the major administrative correctional centre in the State, where they were reviewed by a single chest physician with expertise in TB, with the historical information collected at the time of Mantoux screening. Inmates with normal chest $\mathrm{x}$-rays were either allocated to six months of isoniazid prophylaxis, or allocated to have two years of follow-up with chest $\mathrm{x}$-rays. Prison medical officers made the final decision on clinical review. Baseline biochemical evidence of hepatitis (serum transaminases or bilirubin at least twice the upper limit of normal), clinical or biochemical evidence of chronic liver disease, and likely poor compliance were considered contraindications to isoniazid prophylaxis. Isoniazid was administered as a daily directly observed $300 \mathrm{mg}$ dose with $25 \mathrm{mg}$ vitamin $\mathrm{B} 6$.

Inmates whose Mantoux tests were negative after the two rounds of screening were offered HIV testing. If this was negative, they were not followed any further. Mantouxnegative people who declined HIV testing were offered a single chest x-ray. Diagnosed HIV-positive, Mantouxnegative inmates who were contacts of the cases were assessed for isoniazid prophylaxis.

Details of prisoners released before completed screening and assessment were passed onto the State TB coordinator for follow-up in the community. 


\section{RESULTS}

Nine hundred and forty-three male inmates were identified as contacts of the two infectious cases. Of these inmates, 623 ( 66 per cent) were screened at the first round. The remaining 320 ( 34 per cent) had been released before screening. Of the 623 screened in correctional centres, 255 ( 41 per cent) were Mantoux-positive in the first round of screening (including 30 per cent of the Australian-born and 68 per cent of overseas-born inmates). Of the 368 Mantoux-negative inmates who had been screened in correctional centres, 150 were screened a second time in correctional centres, and of these, 22 (15 per cent) tested Mantoux-positive.

A total of 270 Mantoux-positive and high-risk inmates had received chest $x$-rays at the time of writing. Of these, 208 were allocated to prophylactic isoniazid.

Five hundred and ten staff were also screened with Mantoux tests; 176 ( 35 per cent) were Mantoux-positive.

No cases of active TB were detected among inmates or staff.

\section{DisCusSiON}

An increase in TB occurred throughout the world in the latter half of the $1980 \mathrm{~s}$. Total notifications increased to almost 3.8 million cases, and notification rates increased by 20 per cent to a global rate of $74.6 / 100,000$ in $1990^{1}$. Increases were experienced in most developing regions, and also the USA. Crude TB incidence rates in NSW increased from an historical low of $5.2 / 100,000$ in 1986 to $7.6 / 100,000$ in 1995. The latter rate is still low by international standards.

Overseas studies indicated that correctional centres are potentially important in the propagation of TB, and probably contributed to the recent increase observed in the USA. In a New York county, for example, cases associated with correctional centres comprised 24 per cent of all cases in 1988-90. The potential for transmission in correctional centres was further highlighted by the 1991 outbreak of multi-drug resistant tuberculosis (MDR-TB) in a New York correctional centre which resulted in the deaths of seven HIV-positive inmates and one staff member ${ }^{3}$. High rates of HIV infection, HIV and TB co-infection, frequent movements of inmates, high rates of incarceration, crowding 4 , and poor ventilation, have all contributed to TB transmission in US prisons $s^{5}$. In contrast, HIV and TB co-infection and MDR-TB are not important features of the epidemiology of TB in NSW ${ }^{6,7}$, and rates of HIV in the inmate population are not high (Butler $\mathrm{T}$, unpublished data). However, there are features that potentially facilitate the transmission of TB in the NSW correctional centres, particularly frequent movements of inmates $(30,000$ movements a year), and the presence of inmates from high prevalence countries.
This preliminary Mantoux screening data indicate a high prevalence of positive Mantoux reactions within correctional centres. However, this needs to be interpreted cautiously, in view of the over-representation of high prevalence groups in correctional centres, and the characteristics of the inmates tested as a result of contact tracing, who were not necessarily representative of the population of inmates as a whole. The risk of infection with $M y$ cobacterium tuberculosis due to contact with the infectious cases is the subject of ongoing analysis.

Contact tracing affords a method of disease control that is potentially useful. However, it is logistically difficult, and loss to follow-up and non-compliance are likely to be significant $t^{8}$. The potential for multiple contacts is high in correctional centres, and successful disease control through contact tracing is enhanced by prompt diagnosis.

To reduce the risk of TB transmission further, education of staff and active surveillance for cases has already been instituted in NSW correctional centres. The problems encountered in a larger contact tracing effort in correctional centres underline the importance of a systematic approach to TB control in the correctional centres. Further analysis of data from this investigation will help in the formulation of further recommendations on both future contact tracing efforts and the value of routine screening of inmates.

\section{ACKNOWLEDGMENTS}

We gratefully acknowledge the assistance and cooperation of Maria Hatzdimitris and Phil Brown of the Corrections Health Service, Kiam Lao and others from the Department of Corrective Services who helped with information retrieval, governors of the correctional centres, Greg Sam from South Eastern Region Public Health Unit, Meg Winks (former State Tuberculosis Coordinator), and Peter Massey (acting State Tuberculosis Coordinator).

1. Raviglione MC, Snider DE, Kochi A. Global epidemiology of tuberculosis, morbidity and mortality of a worldwide epidemic. JAMA $1995 ; 273: 220-226$.

2. Pelletier AR, DiFerdinando GT Jr, Greenberg AJ, Sosin DM, Jones WD Jr, Bloch AB, Woodley CL. Tuberculosis in a correctional facility. Arch of Int Med 1993; 153(23):2692-95.

3. Valway S, Richards B, Kovacovich J, Griefinger R, Crawford J,

Dooley S, et al. Outbreak of Multi-Drug resistant tuberculosis in a New York State Prison, 1991. American Journal of Epidemiology 1994; 140(2): 113-122.

4. MacIntyre CR, Kendig N, Birago S, Graham NMH. Impact of tuberculosis control measures and crowding on incidence of tuberculosis in Maryland Prisons. Proceedings of the Australasian Epidemiological Association Annual Conference, Volume 2, 1995.

5. Centres for Disease Control. Prevention and control of tuberculosis in correctional facilities. MMWR 1996; 45:RR-8.

6. McAnulty J, Rubin G, Levy M. Mycobacterial disease and AIDS in New South Wales. Med J Aust 1992; 137:119-121.

7. Curran M, Dawson D. Tuberculosis in Australia: bacteriologically confirmed cases and drug resistance, 1993. Comm Dis Intell 1995; 19:343-345.

8. Alcabes P, Vossenas P, Cohen R, Braslow C, Michaels D, Zoloth S. Compliance with isoniazid prophylaxis in jail. Amer Rev Resp Dis 1989; 140(5):1194-97. 